\title{
Anatomical Features Facilitating Supercooling of the Flower within the Dormant Peach Flower Bud
}

\author{
H.A. Quamme \\ Agriculture and Agri-Food Canada, Research Centre, Summerland, B.C., VOH-1Z0, Canada \\ Wei Ai Su ${ }^{1}$ \\ Shanghai Institute of Plant Physiology, Academica Sinica, 300 Fonglin Rd., Shanghai, China 200032 \\ L.J. Veto ${ }^{2}$ \\ Agriculture and Agri-Food Canada, Research Centre, Summerland, B.C., VOH-1ZO, Canada \\ Additional index words. freeze injury, cold resistance, electron microscopy, Prunus persica
}

\begin{abstract}
Excision of the flower from the peach [Prunus persica (L.) B atsch.] flower bud raised the 50\% injury temperature of flowers (cooled at 1C/hour) from -18 and -20C to -10 and $-13 \mathrm{C}$ on two test dates, 26 Feb. 1988 and 5 D ec. 1990, respectively. Ice inoculation of the excised flowers at $-3 \mathrm{C}$ further raised the $50 \%$ injury temperature to -7 and $-8 \mathrm{C}$ for the two dates, respectively. These observations suggest that supercooling is a true mechanism for avoiding freezing injury. Low temperature scanning electron microscopy of freeze fractured cells verified that the flower froze intracellularly, whereas the subtending tissue froze extracellularly. Ice inoculation of the flower and the flower bud axis from which the scales were removed demonstrated that a barrier to ice propagation (effective to -11C) from the flower bud axis to the flower was present. This barrier may involve the provascular strands and a cell zone at the flower base (BZ) that were devoid of intercellular spaces. These tissues also had smaller cells, smaller vacuoles, greater ratio of cell wall thickness to cell size than tissue just below the BZ, which may result in greater cell rigidity and restriction of extracellular freezing. The cells outside the provascular strands at the base of the flower were also lacking in intercellular space, were smaller in size, and had a higher ratio of cell wall thickness to cell size compared to cells near the base of the scales. In the intact flower buds in which the flowers supercool below -11C, the presence of the first and second scales was important to full expression of supercooling because their removal raised the supercooling point, whereas the removal of lower scales did not. Sequestration of ice by the first two subtending scales during the early stages of freezing may be important to the creation of a dry region at the flower base that prevents ice propagation into the flower at temperatures below -11C.
\end{abstract}

Supercooling of flowers within dormant buds of several genera and woody plant species appears to be a mechanism for avoiding freezing injury. This supercooling is often referred to as deep supercooling as it occurs below the freezing point of the subtending tissue. Deep supercooling has been observed in flower buds of rhododendron spp. (George et al., 1974; Graham and Mullin, 1976), blackberry (Warmund et al., 1988), blueberry (Biermann et al., 1979), flowering dogwood (Sakai, 1979a), forsythia (Nus et al., 1981), Rubus spp. (Warmund et al., 1988), and several Prunus spp. (Burke and Stushnoff, 1978; Quamme, 1974), some conifers (Sakai 1978, 1979b), and in multiple buds of grape (Pierquet and Stushnoff, 1980). Low temperature injury to buds of these species is associated with sudden freezing of a supercooled fraction of water within the bud that was detected by thermal analysis as a lowtemperature exotherm (LTE).

The supposition is that the LTEs of buds are produced by intracellular freezing of the flower because of their sudden occurrence and lethal effects but this has not been verified. Extracellular ice crystals have been seen in the tissue subtending the flower in rhododendron (Ishikawa and Sakai, 1981), peach (Dorsey, 1934; Quamme, 1978) and plum (Dorsey and Strausbaugh, 1923) with aid of a light microscope. However, it has not been possible to determine if intracellular ice is present in the flower with aid of a light microscope (Quamme, 1978).

Received for publication 31 Oct. 1994. Accepted for publication 8 Mar. 1995 Summerland Research Centre contribution no. 790. Wegratefully acknowledge the excellent technical assistance of R.T. Brownlee. The cost of publishing this paper was defrayed in part by the payment of page charges. Under postal regulations, this paper therefore must be hereby marked advertisement solely to indicate this fact. ${ }^{1}$ Research scientist.

${ }^{2}$ Electron microscopist.
The dormant peach flower bud usually contains a solitary flower. Studies of seasonal changes in supercooling of peach flowers indicated that deep supercooling is maintained throughout the season, from flower bud formation in autumn until bud burst in spring (Quamme, 1974, 1983).

It is not clear what prevents the ice propagation from subtending tissue into the peach flower, but several observations suggest that a structural barrier is involved. Killing the flower by freezing it below the supercooling point (Quamme, 1978) or by heating it to 65C for $30 \mathrm{~min}$ (Ashworth, 1982) raised the supercooling temperature but did not eliminate it. Disruption of the flower base by cutting also raised the supercooling point of the flower from below -20 to -10C (Quamme, 1978). Ashworth (1984) observed that in the spring when the xylem elements differentiated, supercooling of the flower was lost. He suggested that ice propagates into the flower through the xylem.

The structure of the tissue subtending the flower also appears important to the full development of supercooling (below -10C) in peach. Ice masses have been observed in the base of the scales and in the pith of the flower bud axis below the flower (Dorsey, 1934; Quamme, 1978). Ice formation in the scales was associated with a decrease in water content at the base of the flower, (Quamme, 1978). It was proposed that water movement to the flower bud scales in the initial stages of freezing created a dry region below the flower that prevented ice propagation into the flower, but it is unknown which, if any, of the scales are essential to full supercooling of the flower.

Inoculation of the flower from the exterior of the flower bud with ice through an excision in the scales at different temperatures raised the killing point of the flower from -25 to $-8 \mathrm{C}$ (Quamme, 1978). Wounding the flower directly with a needle also destroyed the supercooling capacity (Ashworth, 1982). Quamme (1978) 
suggested that the cuticle and epidermis prevented nucleation from the exterior but this hypothesis has not been tested.

The objectives of this study were to determine if freezing injury to the flower within the peach flower bud is avoided by supercooling, if there is an anatomical barrier to ice propagation into the base of the flower, and if the flower bud scales and flower cuticle play a role in maintaining the flower in a supercooled state.

\section{$M$ aterials and $M$ ethods}

Effects of ice inoculation on flower injury and supercooling. All studies were conducted during the winter months of 1987 to 1992 on flower buds produced on shoots from mature 'Redhaven' [Prunus persica (L.) Batsch.] peach trees in orchards at the Summerland Research Centre. The shoots were collected and used immediately or stored at 0C or -3C until used.

Survival of the excised flower, uninoculated and inoculated with ice at $-3 \mathrm{C}$, was compared to the survival of the intact flower within the flower bud. The excision was carried out at $22 \mathrm{C}$ under a stereoscopic microscope, and the tissue was immediately transferred to a petri dish containing moist filter paper. The whole flower bud was cut to include a piece of the shoot attached to the base. The flower was excised by cutting away the scales to expose the flower and then cutting the flower just above the flower bud axis with a sharp scalpel. Ice inoculation of the excised flower was carried out by cooling it to $-3 \mathrm{C}$ in a cold room, placing a small droplet of ice water on the surface of the tissue, and introducing a piece of ice into the water droplet with a pair of tweezers. Whole flower buds were cooled to $-3 \mathrm{C}$, and the base of the flower bud axis was inoculated by dipping the cut surface into ice water and allowing the water to freeze before further cooling. A sample (10) of each inoculated, and uninoculated, excised flowers and the whole flower buds were each placed in separate metal containers at -3C. A set of samples was prepared for each test temperature. The sets of samples were cooled in the cold room to preselected temperatures $2.5 \mathrm{C}$ apart in the range of injury at $1 \mathrm{C} / \mathrm{h}$. At each test temperature, a set of samples was removed from the freezer, thawed at $0 \mathrm{C}$, and then incubated over moist filter paper in petri dishes for three days at 3C. After incubation, the flowers and flower buds were sectioned and observed for browning with a stereoscopic microscope. Flowers that were brown were classified as injured, whereas those that remained normal green were classified as uninjured. The experiment was repeated three times with material collected on each of two dates, 26 Feb. 1988 and 5 Dec. 1990. Micrographs of injured flowers in the bud were made to show the location of injury.

To determine whether there was a barrier to the ice propagation from the flower bud axis into the flower, the flower was examined for the presence of supercooling after the flower bud axis, from which the scales were removed, was inoculated with ice. Exotherm analysis was also performed on inoculated and uninoculated excised flowers, inoculated flowers on flower bud axes, and inoculated whole flower buds as controls. Excised flowers were inoculated on the uncut and the cut surface where the excision was made to determine whether the cuticle and epidermis restricted the ice propagation. Excision and ice inoculation were carried out as described previously. The flower buds were collected for this study on 24 Feb. 1988.

Exotherm analysis of the flower buds and flower bud parts was conducted by noting sudden deflections observed on temperature recordings during cooling. The method used was similar to that described previously (Quamme, 1974) except that the thermocouple (20 gauge, copper-constantan) was attached with silicon grease to the surface of the base of the flower bud or that of the flower. After attachment to the thermocouple, the tissue was placed in a Dewar flask at $-3 \mathrm{C}$ and cooled to below $-30 \mathrm{C}$ at $5 \mathrm{C}$ / h. The tissue temperature was determined with a 3974A data logger interfaced with a computer (model 300; Hewlett-Packard, Rockville, Md.).

Effect of scale removal on LTE. The importance of the flower bud scales to supercooling of the flower was determined by scale removal from the flower bud base. The LTE temperature was measured on buds from which varying numbers of scales were removed. The number of scales remaining on the bud axis was counted after the exotherm analysis was run. The collection date for the flower buds used in this study was 7 Feb. 1989. The sample size was 14 to 18, except for flower buds with 5 scales, for which exotherms were determined on 3 flower buds. Analysis of variance was performed on the data using the General Linear Models procedure of SAS Institute (1985).

Low-temperature scanning electron microscopy (LTSEM) of freeze-fractured floral parts. To confirm if cells within the flower froze extracellularly or intracellularly, flower buds (5) were frozen intact on the shoot to $-23 \mathrm{C}$ (below the LTE, -18C) at a cooling rate of $1.2 \mathrm{C} / \mathrm{h}$, rewarmed to a holding temperature of $-12 \mathrm{C}$ at a rate of $5 \mathrm{C} / \mathrm{h}$. Flowers and flower bud axes with the scales removed were excised from flower buds, and mounted on a precooled cryospecimen stub at the holding temperature with the aid of a binocular microscope. The sample on the cryo-specimen stub was quenchfrozen in supercooled liquid nitrogen at -209C with a cryoapparatus (K-1250; Emiteck, Ashford, UK). After quench-freezing, the sample was fractured at and sputter-coated in the cryoapparatus with gold-192C (Dubochet et al., 1985; Steinbrecht and Zierold, 1987). The gold-coated fractured floral parts on the cryospecimen stub were transferred and maintained at $-123 \mathrm{C}$ during examination (from 10 to $25 \mathrm{kV}$ ) with scanning electron microscope (SEM) (JSM-840A; JEOL Ltd., Tokyo) fitted with an Emiteck LTSEM cryo-stage. Similar observations were made on excised flowers that were quench-frozen from room temperature.

Peach flower bud anatomy. For SEM, the flower buds were stored in the buffered glutaraldehyde solution $(5 \%, 0.07 \mathrm{~m}, \mathrm{pH}$ 6.8 ), cut longitudinally along the flower axis and then post-fixed in $2 \%$ osmium tetroxide. These fixed samples were dehydrated in ethanol, critical-point dried using $\mathrm{CO}_{2}$ with a $\mathrm{CPD} 020$ criticalpoint dryer, (Balzer's Fürstentum, Liechtenstein) mounted on aluminum stubs, and sputter-coated with gold using a sputtercoater (Desk II; Denton Vacuum Inc., Cherry Hill, N.J.). Samples were examined with the SEM, operated at $25 \mathrm{kV}$.

Flower buds were collected for anatomical investigation on 6 Jan. 1988, preserved with 5\% glutaraldehyde in Sorenson's buffer $(0.07$ $\mathrm{M}, \mathrm{pH}$ 6.8), and then vacuum infiltrated with a second change of the same buffered glutaraldehyde solution (Sabatini et al., 1963). The samples were washed in Sorenson's buffer (six times for $0.5 \mathrm{~h}$ each) and stored at $2 \mathrm{C}$ in the same buffer for several days. Several flower buds were dissected in buffered glutaraldehyde to include the flower and flower bud base, and these parts were post-fixed in $2 \%$ osmium tetroxide in Sorenson's buffer at 4C (Hayat, 1986). After fixation in $2 \%$ osmium tetroxide, the flower bud parts were dehydrated in an ethanol gradient, vacuum infiltrated, using propylene oxide as an intermediate fluid, and then embedded in JEMBED 812 epoxy resin for sectioning (Luft, 1961). Longitudinal, 2- $\mu$ m-thick (semi-thick) sections of the base of a flower and the upper flower bud axis were cut with a microtome (Ultracut E; Reichert-Jung, Vienna) using a glass knife. Serial semi-thick sections (with a glass knife) and serial ultra-thin sections (50-60 nm, with a diamond knife) were cut from another flower bud using the same ultramicrotome.

The parts of the flower that were sectioned are indicated in Fig. 1. 


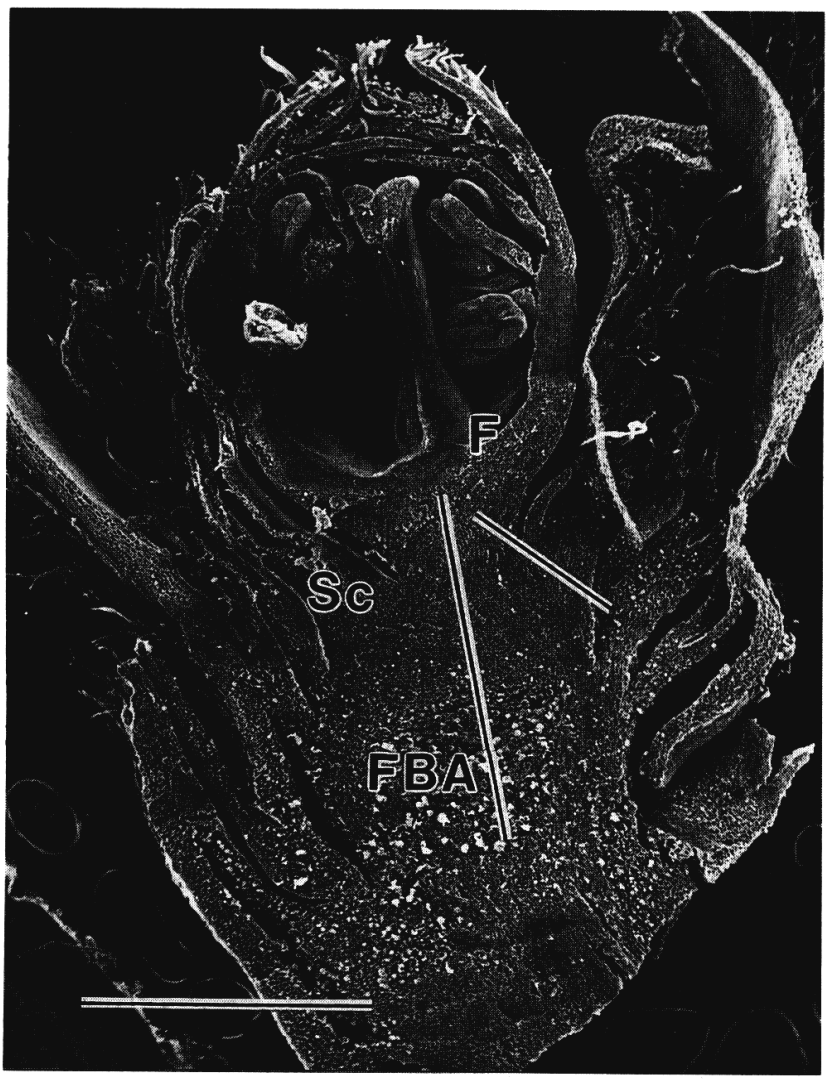

Fig. 1. A scanning electron micrograph image of a longitudinal section of a peach flower bud shows the flower (F), the flower bud scales $\left(\mathrm{Sc}_{\mathrm{C}}\right)$, and the flower bud axis (FBA). The line at the base of the flower bud indicates the axis where cross sections were cut and the line from the flower to the second scale indicates the axis where longitudinal sections were made. Bar $=1 \mathrm{~mm}$.

The serial sectioning began about $0.4 \mathrm{~mm}$ below the first scale subtending the flower and ended just below the ovary. This sectioned region was $1.2 \mathrm{~mm}$ long. Semi-thick sections were also cut with a glass knife longitudinally through the base of the first and second flower bud scales and the flower (Fig. 1).

Semi-thick sections were stained with toluidine blue and basic fuchsin in sodium carbonate solution (Lewis and Knight, 1977) and examined with a photomicroscope (Carl Zeiss, Oberkocken, Germany). The ultra-thin serial sections were mounted on copper grids, stained with uranyl acetate followed by Reynold's lead citrate, and viewed with transmission electron microscope TEM; (JEOL $100 \mathrm{CX}$ II) at $80 \mathrm{kV}$.

Cell size measurements were made from micrographs of the semi-thick serial cross sections through the flower base $(0.1 \mathrm{~mm}$ apart) and longitudinal sections at the base of the first two subtending scales and the flower (four sections). Cell diameter (30 cells) was measured in each of the series of cross or longitudinal sections and expressed as cell cross sectional area. The cell wall thickness of the same cells was measured from micrographs of the sections. The ratio of cell wall thickness to cell cross sectional area was also determined. The percentage of intercellular space was determined by area weight ratios from the micrographs.

\section{Results}

Effects of ice inoculation on flower injury and supercooling. The excised flowers, both inoculated and uninoculated with ice, were injured at a higher temperature than intact flowers in the flower bud (Fig. $2 \mathrm{~A}$ and B). 50\% injury determined from the spline interpolation occurred to the inoculated excised flower at -8 and $-7 \mathrm{C}$, to the uninoculated excised flower at -10 and $-13 \mathrm{C}$, and to the intact flower in the flower bud at, -18 and $-20 \mathrm{C}$ on the first and second collection dates, respectively. The subtending tissue of whole buds did not show browning at all test temperatures.

A LTE occurred on the time-temperature profile of the uninoculated excised flower (Fig. 3A) as it did on that of the whole flower bud (Fig. $3 \mathrm{E})$. The mean LTE temperature determined on the excised flower was $7 \mathrm{C}$ higher than that of the inoculated whole flower bud (Fig. $3 \mathrm{~A}$ and F). The increase in LTE temperature of the excised flower coincided with the higher killing temperature that occurred in the excised flowers in the first experiment. A slight deflection was sometimes present on the time-temperature profile of the ice inoculated flower at a temperature just below that at which cooling was begun, but it was neither as sharp nor as high as the deflections on the time-temperature profile of the excised uninoculated flower. Inoculation of the excised flower with ice placed on the cut surface of the flower base (Fig. 3B) was as effective in preventing supercooling as inoculation of the excised flower with ice placed on the uncut exterior of the flower (Fig. 3C). The LTE was detected in the intact flower on. the inoculated flower bud axis from which the scales had been
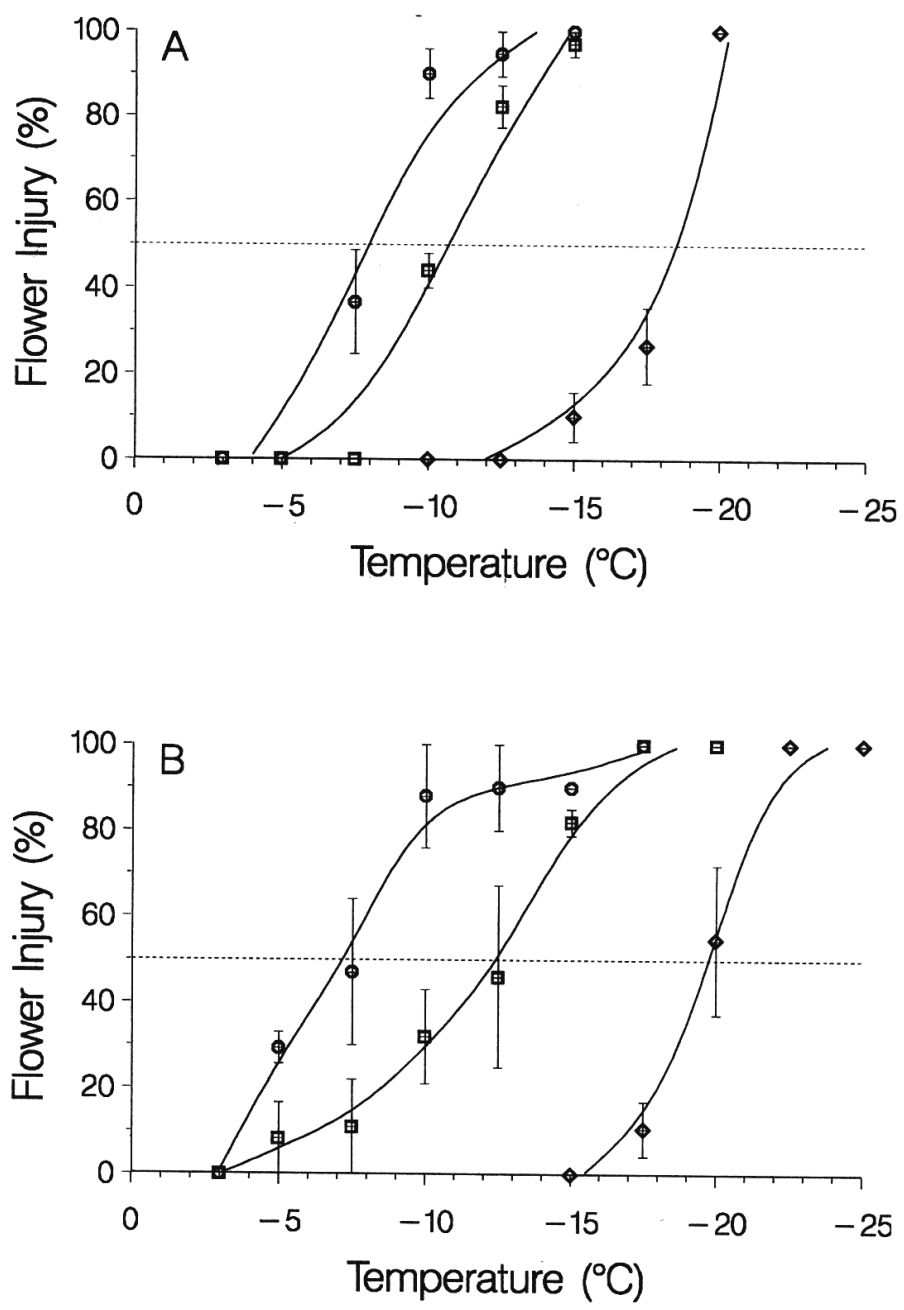

Fig. 2. Freezing injury to flowers excised from flower buds and then inoculated with ice at $-3 \mathrm{C}$ before freezing ( $\bigcirc$ ), uninoculated flowers excised from flower buds ( $\square$ ), and flowers intact in the inoculated flower bud $(\diamond)$ on two collection dates, (A) 26 Feb. 1988 and (B) 5 Dec. 1990. Each value represents the mean \pm SE of three experiments. Lines were drawn through the points using spline interpolation (SAS/Graph, SAS Institute., 1985). The dashed reference line indicates $50 \%$ level of injury to the flowers. 


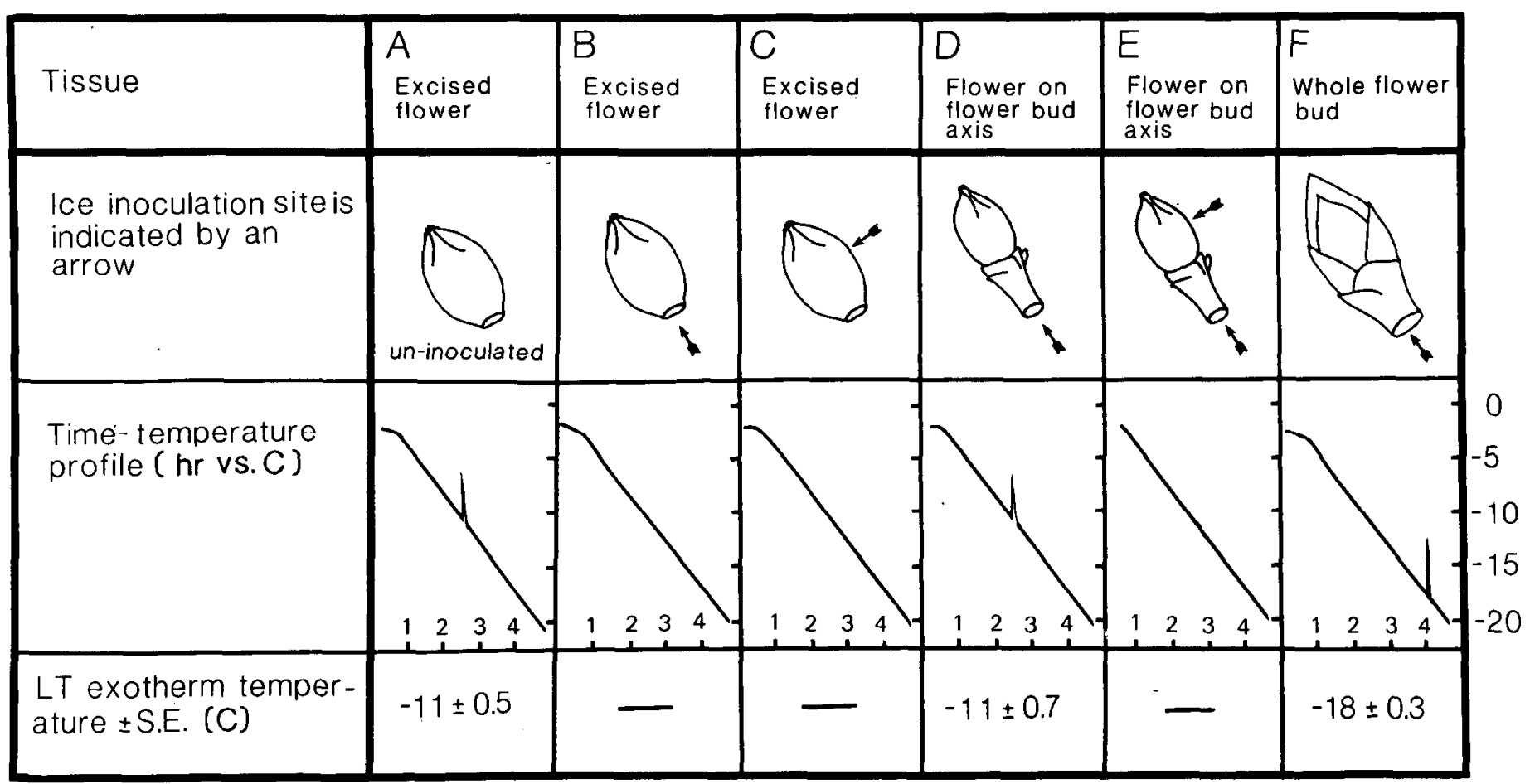

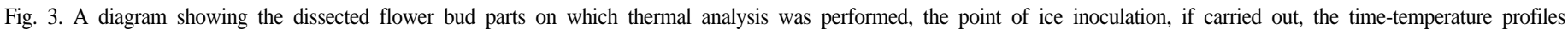
of the flower bud or its dissected parts, and the mean temperature $\pm \mathrm{SE}(\mathrm{n}=12)$ at which the low temperature exotherm occurred, if present. Panels A to F indicate the treatment and the results.

removed (Fig. 3D) at the same temperature as that of the uninoculated excised flower (Fig. 3A). Inoculating the flower on the bud axis at the surface of the flower and flower bud axis eliminated the LTE (Fig. $3 \mathrm{E})$ as it did with the excised flower (Fig. 3B).

The effect of scale removal on the LTE. Progressive removal of the scales from the base of the flower bud to the second scale below the flower did not affect the LTE temperature (Table 1).

Removal of all scales, except for the first scale subtending the flower, significantly raised the LTE temperature from $-18 \mathrm{C}$ to 14C. A significant further rise in LTE temperature did not occur with removal all scales including the first scale subtending the flower.

LTSEM observations on freeze-fractured floral parts. Cell appearance of freeze-fractured flowers subjected to two freezing treatments, quench-freezing from room temperature and quenchfreezing from $-12 \mathrm{C}$ after freezing to $-23 \mathrm{C}$ followed by rewarming, was similar as is shown for floral tube cells (Fig. 4 A and B). The floral tube cells were typical of both treatments and appeared to be neither shrunken nor deformed. Some empty intercellular spaces were observed between the floral tube cells. The cell vacuoles from

Table 1 . The effect of scale removal on the low temperature exotherm (LTE) temperature.

\begin{tabular}{ll}
\hline $\begin{array}{l}\text { No. of scales remaining } \\
\text { on the flower bud axis }\end{array}$ & LTE $\left({ }^{\circ} \mathrm{C}\right)$ \\
\hline 0 & $-12.8 \mathrm{a}$ \\
1 & $-13.7 \mathrm{a}$ \\
2 & $-18.3 \mathrm{~b}$ \\
3 & $-17.3 \mathrm{~b}$ \\
4 & $-19.2 \mathrm{~b}$ \\
5 & $-18.5 \mathrm{~b}$ \\
Whole flower bud (5-8 scales) & -18.7 \\
SE & \pm 1.0
\end{tabular}

'Means ( $\mathrm{n}=3$ to 18 ) within column followed by the same letter are not significantly different by Duncan's new multiple range test at $P \leq 0.05$. both treatments appeared to be filled with vitrified ice and extracellular ice crystals were not detected. The presence of ice between the plasma membrane and cell wall was not detected. Large extracellular ice crystals were observed within the flower bud axis that were frozen to $-23 \mathrm{C}$, rewarmed to $-12 \mathrm{C}$, and quench-frozen (Fig. 4C). Cells within the flower bud axis appeared to be elongated.

Anatomy of the flower base. Longitudinal sections of flower buds showed typical injury to the flower that was observed after freezing to just below the LTE temperature (Fig. 5A). Injury appeared to be confined to the flower. The scales and the tissue subtending the flower remained a normal green color. The margin of injured tissue at the base of the flower was discrete.

Provascular strands extending from the bud axis into the flower were revealed in longitudinal sections cut through the base of the flower. A zone of small, cytoplasmically dense cells (BZ) appeared to connect the strands at the base of the flower (Fig. 5B). The presence of the $\mathrm{BZ}$ was verified in cross sections of the flower base (Fig. 5C). The BZ coincided approximately with the boundary of injured floral tissue in flower buds frozen to below the LTE temperature.

Cells within the provascular strands and BZ tended to have small vacuoles and intercellular space was absent (Fig. $5 \mathrm{C}$ and D). In contrast, cells within the tissue below the BZ had large vacuoles and intercellular space was present (Fig. 5E). The cells in the flowerjust above the BZ were larger than cells in the BZ and more highly vacuolate, but intercellular space was absent (Fig. 5F).

Intercellular space decreased in cross section from below the margin of the BZ and was absent from tissue adjacent to the top of the BZ (Fig. 6). Cell cross sectional area of cells from the BZ was one quarter or less than that of cells from below the BZ. Cells increased in cell cross sectional area above the BZ. Cell wall thickness decreased from below to above the BZ, but the decrease in cell wall thickness was not constant. Increases in cell wall thickness compared to lower cross sections occurred below and at the BZ. The ratio of cell 

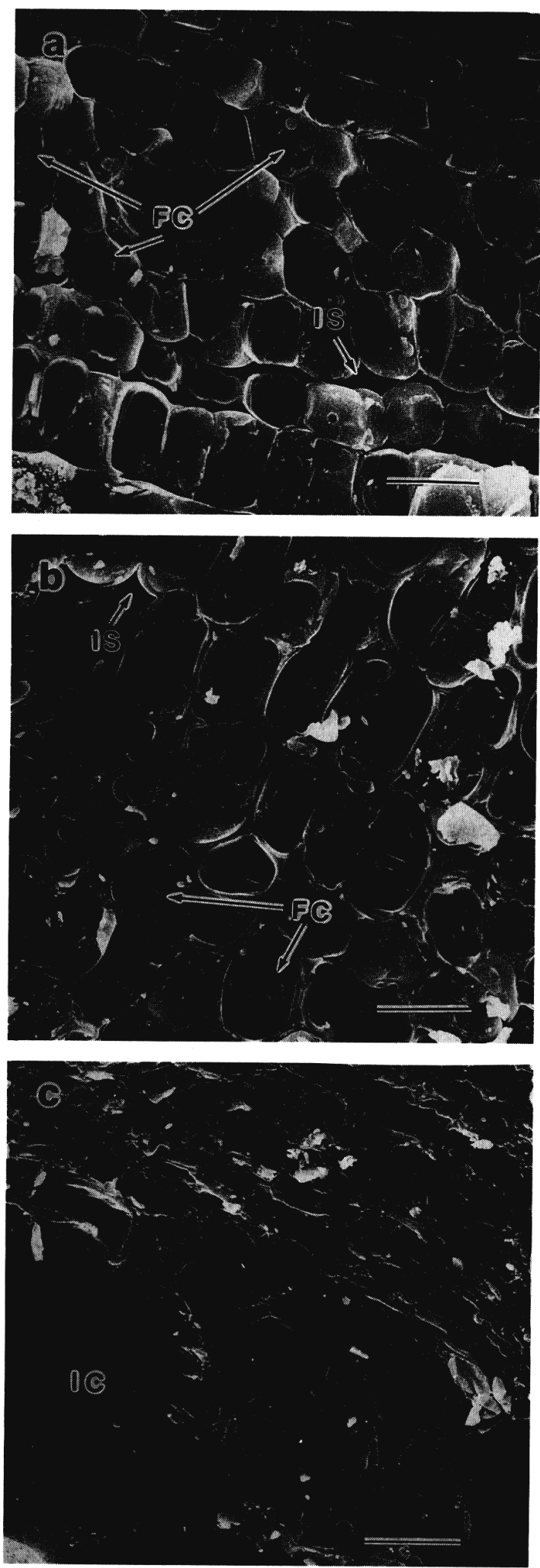

Fig. 4. Low temperature scanning electron micrographs of the fracture surfaces of peach flower buds that were quench-frozen in supercooled liquid nitrogen. Appearance of freeze-fractured cells in the floral tube that were (A) quenchfrozen from room temperature and (B) quench-frozen from the $-12 \mathrm{C}$ holding temperature after freezing to $-23 \mathrm{C}$ (below the low temperature exotherm), at $1.2 \mathrm{C} / \mathrm{h}$. Ice is absent in the intercellular spaces. (C) Extracelluar ice in freeze fracture tissue from the base of a flower bud scale after quench-freezing from the $-12 \mathrm{C}$ holding temperature. Abbreviations: $\mathrm{FC}=$ freeze fractured cells, IS = intercellular space, and IC $=$ extracelluar. Bars $=20 \mu \mathrm{m}$. wall thickness to cell cross sectional area decreased from below to above the BZ, but there was a sharp increase at the BZ to over twice that of any of the other serial cross sections.

Intercellular space and cell cross sectional area were observed to decrease from the scales to the flower in longitudinal sections made at the base of subtending scales into the base of flower (Fig. 7). Measurements of cell wall thickness from the scales to the flower base remained constant, whereas the ratio of cell wall thickness to cell cross sectional area increased six times in the same region (Fig. 8).

\section{Discussion}

The nucleation temperature of supercooled, excised flowers was higher than that of intact flowers within the flower bud, which agrees with a previous observation (Quamme, 1978). Initiation of ice formation in the excised flower by ice inoculation further raised the temperature at which injury occurred. The flower appeared to lack resistance to freezing and to be dependent on supercooling for survival. Ishikawa and Sakai (198 1) also found that rhododendron flowers were injured by ice inoculation at temperatures just below freezing and suggested that supercooling was a mechanism for avoiding freezing injury. In both species supercooling of the flower persisted from autumn through winter until bud break (Ishikawa and Sakai, 1981; Quamme, 1983).

The LTSEM observations that extracellular ice was absent in the flower, and that flower cells did not appear to be shrunken after freezing slowly to below the LTE temperature followed by quenchfreezing in supercooled liquid nitrogen substantiates the hypothesis that the flower freezes intracellularly. Furthermore, the plasma membrane did not appear to detach from the cell wall to allow ice to form between the cell wall and the plasma membrane.

Rewarming the flower to $-12 \mathrm{C}$ during transfer to the freezefracture apparatus after freezing to below the LTE was not thought to affect the presence of ice in the flower tissue because its thawing point was previously determined to occur at -2 to -3C (Quamme, 1983). Extracellular ice was present in tissue subtending the flower that was frozen slowly to below the LTE followed by quench-freezing.

The lack of a distinct exotherm on the time-temperature profile of the inoculated excised flower indicated that inoculation suppressed, if not eliminated, supercooling. It was not determined whether injury to the inoculated bud occurred as a result of intracellular or extracellular freezing. If intracellular freezing occurred, it progressed slowly through the tissue and did not produce a sudden deflection on the time-temperature profile as occurred in the uninoculated flower. Small exotherms produced in the range of injury in some flowers indicated that progressive intracellular freezing probably occurred.

The flower on the flower bud axis from which the scales were removed exhibited a LTE if only the flower bud axis was ice inoculated. If both the flower and the flower bud axis were ice inoculated, no LTE was present. This indicates existence of a barrier to ice propagation into the flower from the flower bud axis. However, the temperature to which the flower supercooled on the flower bud axis without scales was higher $(-11 \mathrm{C})$ than that of the flower within the intact flower bud with scales (-18C), which suggests that the scales are required for the barrier to be fully effective. The barrier to the ice propagation appears to be a morphological feature because supercooling was not eliminated in freeze-killed (Quamme, 1978) or heat-treated flower buds (Ashworth, 1984).

The barrier to ice propagation into the flower may involve the basal structure of the flower. The BZ and adjoining vascular 

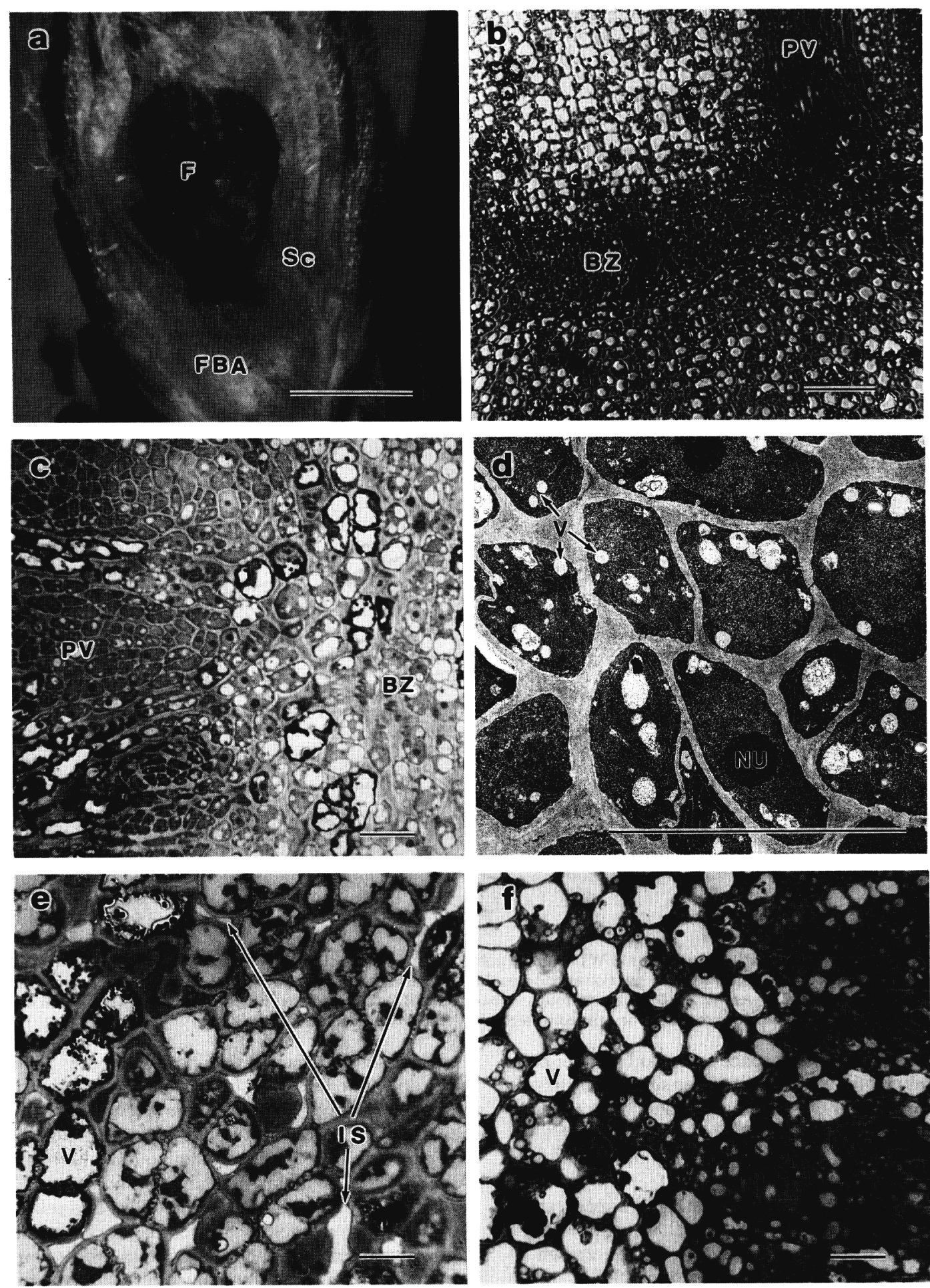

Fig. 5. (A) A longitudinal section of the flower bud that has been frozen below the low temperature exotherm, incubated at room temperature for 3 days, and cut to show the flower and subtending tissue. The injured flower became brown (dark colored in the micrograph), whereas the scales and flower bud axis remained normal green (light colored in the micrograph). (B) The provascular strands and basal zone are shown in a longitudinal section of the flower base that was stained with toluidine and azure blue. (C) A cross section stained with toluidine and azure blue through the bazal zone into the provascular strands shows the absence of intercellular spaces and small cell size of these tissues. (D) The vacuoles of cells in the bazal zone appeared small and numerous in a transmission electron micrograph. Cell nuclei appeared to be prominent. (E) The presence of intercellular spaces is seen in the toluidine and azure blue stained cross section of the bud axis below the bazal zone of the flower. Large vacuoles were observed in this tissue. (F) A cross section of the flower above the basal zone stained with toluidine and azure blue shows the provascular strands and parenchyma cells inside the strands at the base of the flower. The parenchyma cells inside the strands were observed to be large and contain large vacuoles. Abbreviations: $\mathrm{F}=$ flower, $\mathrm{SC}=\mathrm{scale}$, $\mathrm{FBA}=$ flower bud axis, $\mathrm{PV}=$ provascular strands, $\mathrm{BZ}=$ basal zone, $\mathrm{V}=$ vacuole, $\mathrm{NU}=$ cell nucleus, and $\mathrm{IS}=$ intercellular space. $(\mathbf{A}) \mathrm{Bar}=1 \mathrm{~mm} .(\mathbf{B}, \mathbf{C}, \mathbf{E}$, and $\mathbf{F}) \mathrm{Bar}=20 \mu \mathrm{m}$. (D) $\mathrm{Bar}=5 \mu \mathrm{m}$ 


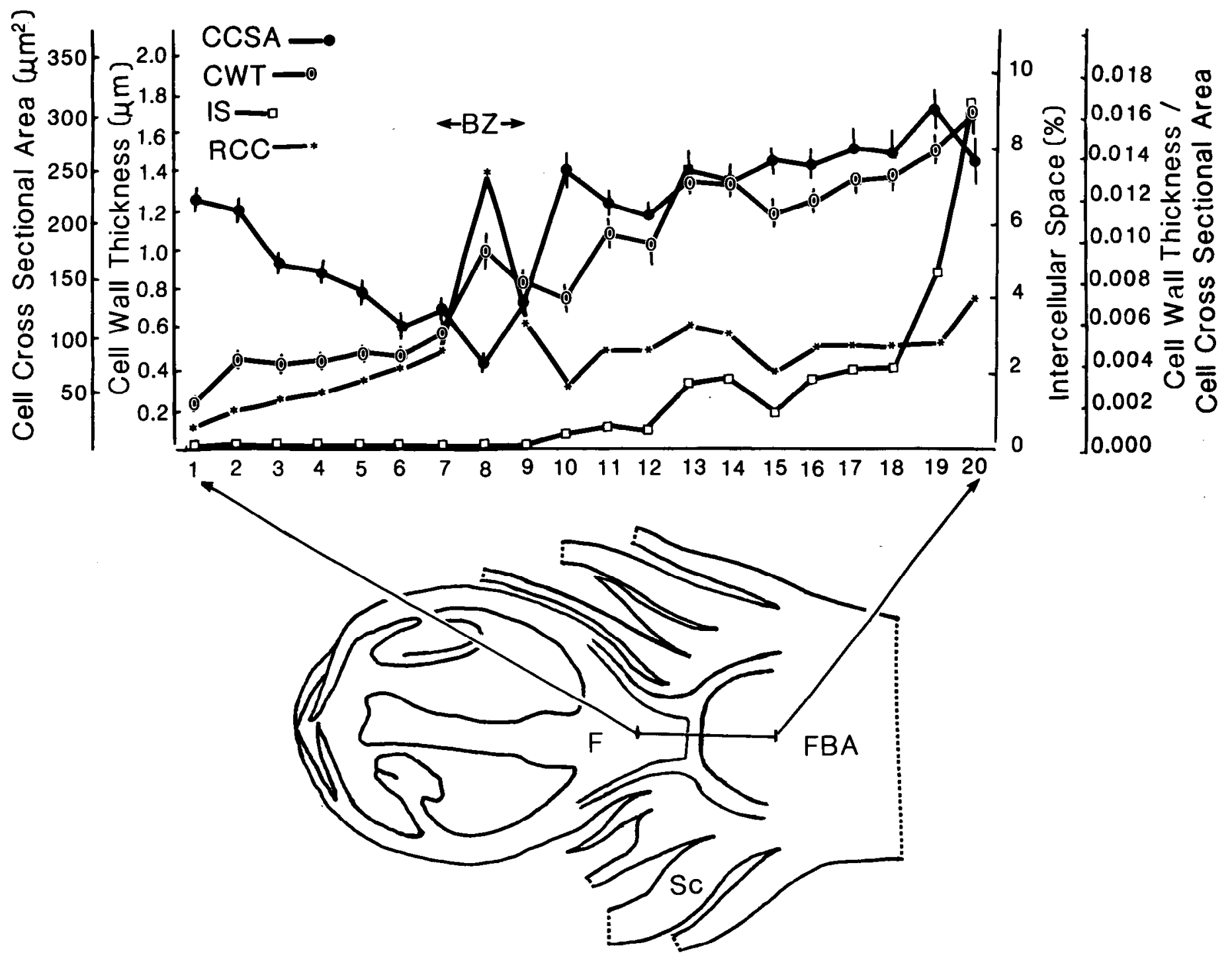

Fig. 6. The cell cross sectional area (CCSA), cell wall thickness (CWT), ratio of cell wall thickness to cell cross sectional area (RCC), and percent intercellular space (IS) measured in cross sections cut from the flower base (F) and flower bud axis (FBA). The region of the flower bud that was sectioned as indicated in the adjacent diagram in longitudinal section. The sections were cut at $0.1 \mathrm{~mm}$ apart through the basal zone (BZ). The numbers on the $\mathrm{x}$-axis indicates sections in which measurements were made. Sc indicate the scales. Sections are from the BZ designated by arrows. Vertical bars denote \pm SE $(\mathrm{n}=30)$.

strands were devoid of intercellular spaces, and had smaller cells with smaller vacuoles and thicker walls than the subtending tissue. The tissue to the exterior of the provascular strands near the base of the flower had similar cell characteristics to that of BZ. In flower buds frozen to just below the LTE, the boundary of injury to the flower appeared to coincide with the BZ.

The presence of the BZ in peach buds may be similar to an anatomical feature found in some conifer buds that supercool. The buds of Abies and Larix spp. that supercool have a crown of medullary tissue that is absent in other conifers. (Sakai, 1978, 1979b). Removal of the medullary crown tissue from the excised shoot primordium of Abies homolepsis raised the supercooling point from -25 to $-15 C$ (Sakai, 1979b).

In Prunus spp., an abscission zone is present at the base of the pedicel at the point of stem attachment in the fruit (Esau, 1953). The BZ may correspond to the early development of an abscission zone but it was not verified in this study.

The absence of intercellular spaces may be critical to preventing ice propagation into the flower. Acid fuchsin (Quamme, 1978) and azosulfamide (Ashworth, 1982) uptake did not penetrate the flower which indicates a fine pore structure. Water held in fine pores does not freeze as bulk water but tends to have a lower melting point and vapor pressure depending on pore size. The critical pore size for this effect to occur appears to be $6 \mathrm{~nm}$. Cell wall pore size was not determined, but in absence of intercellular spaces, it could be in this size range (Ashworth and Abeles, 1984).

The small cell size, lack of vacuoles, and relatively thick cell wall structure may increase the resistance of the cells at the base of the flower to cell wall deformation that results from extracellular freezing. Rigid cell structure may be critical to restricting extracellular freezing and ice propagation along cell walls.

The presence of a single LTE indicates that ice propagates suddenly throughout the flower when freezing begins. LTSEM conducted in this study confirms the occurrence of intracellular freezing. Previously, flower tissue at $-15 \mathrm{C}$ was observed to turn from a translucent, greenish to whitish color when inoculated with ice. The change in flower coloration, which spread from the point of inoculation, was possibly caused by intracellular freezing (Quamme, 1978). Once intracellular freezing begins it may proceed from cell to cell through the pit structure. 


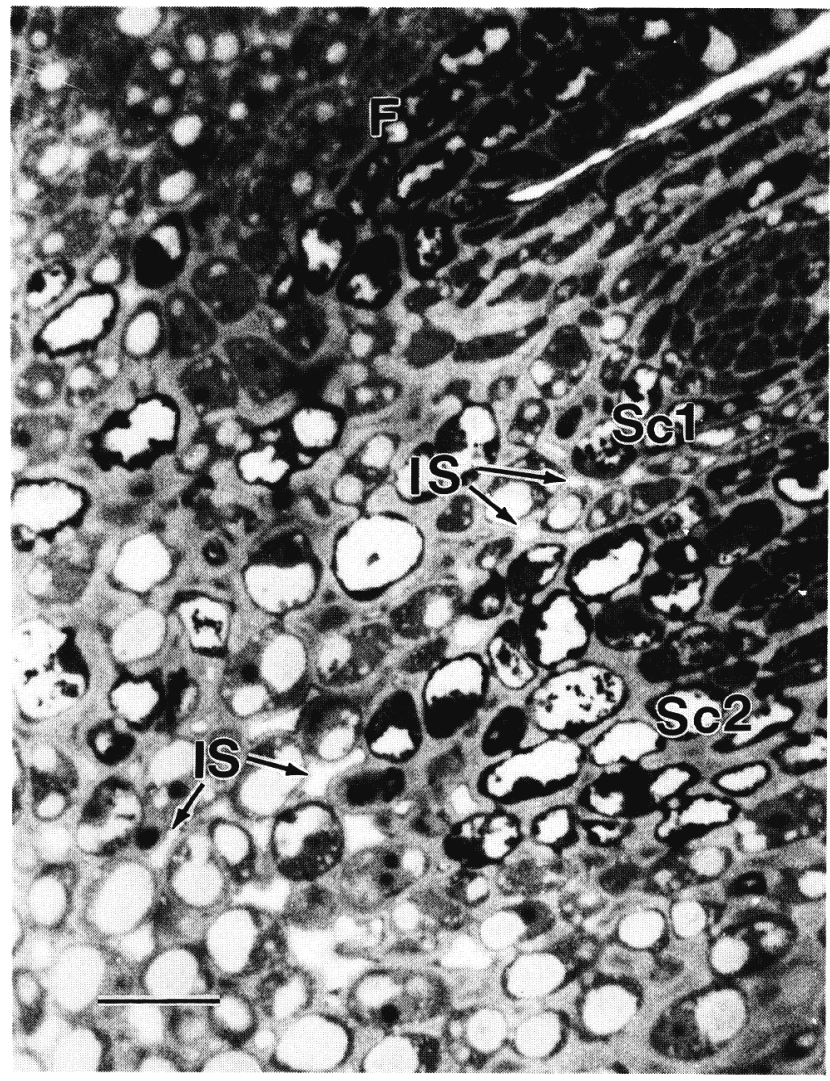

Fig. 7. A longitudinal section of the flower at the base of the first two upper scales (Sc 1 and Sc 2) near the flower stained with toluidine and azure blue shows the parenchyma cells outside procambium strands. Cells near the periphery of the flower tend to be smaller and contain smaller vacuoles than other regions. Intercellular spaces (IS) were observed at the base of the scales. The bar $=20 \mu \mathrm{m}$.

The first and second scales subtending the flower appear to be critical to full development of supercooling of the flower within the intact flower bud. The removal of these scales raised the supercooling point but the removal of lower scales did not. The scales appear to sequester ice at their base on freezing (Dorsey, 1934; Quamme, 1978). Voids in the tissue of dormant peach flower bud axis have been found where ice forms (Ashworth et al., 1989). Water appears to be withdrawn from the base of the flower to these points of ice sequester during the initial stages of freezing. Lowering the water content at the flower base may create a dry region that prevents ice propagation into the flower (Quamme, 1978). The possibility of a discontinuity in the liquid phase that allows ovaries of peach and plum flowers to supercool was also demonstrated by Cary (1985).

Sakai (1979a) termed the process of water translocation from supercooled tissues to adjacent tissues as "extraorgan" freezing. It occurs in seeds and in vegetative and floral buds of several woody plants (Sakai and Larcher, 1987). Extraorgan freezing was considered by Sakai and Larcher (1987) to be a tolerance mechanism rather than an avoidance mechanism because they suggested that water is withdrawn from the supercooled tissue to freezing sites in most plant tissues subjected to natural cooling rates. However, the flower within the peach flower bud exhibits supercooling throughout the winter (Quamme, 1978; Quamme, 1983) and when it is stored at subzero temperatures (-3C for 3 weeks, $-5 \mathrm{C}$ for 1 week, and $-10 \mathrm{C}$ for 5 days) (Quamme et al., 1982). Furthermore, we have provided evidence that nucleation of the supercooled flower is dependent on presence of an anatomical barrier at the flower base. Peach flower bud survival at freezing temperatures appears to be a true avoidance mechanism.
Survival of peach flower buds by freezing avoidance is noteworthy because it is not clear what evolutionary advantage this adaptation would have. Possibly, it is a feature associated with early flower development in the spring, and subsequent early fruit development in summer, (Quamme, 1991) but this is speculative.

Inoculation of the flower with ice on the surface of the cuticle was as effective in preventing supercooling as inoculation of the flower with ice at the cut surface. Therefore, the cuticle and epidermis appeared to be a weak barrier to the ice propagation into the flower from the exterior. The scales enclosing the flower may act to exclude water from the surface of the flower that could inoculate the flower during freezing. Otherwise, freezing rain or dew drops would inoculate the flower.

The overwintering peach flower appears to survive by a mechanism of freezing avoidance. This mechanism is complex and involves a combination of physiological and anatomical features that segregate ice formation in the flower bud and restrict its spread into the flower. In this study, observations indicate that provascular tissue and the BZ at the flower base may be a barrier to ice propagation into the flower and that the first and second scales subtending the flower are important to the full expression of supercooling because they may be sites for sequestering ice.

\section{Literature Cited}

Ashworth, E.N. 1982. Properties of peach flower buds which facilitate supercooling. Plant Physiol. 70:1475-1479.

Ashworth, E.N. 1984. Xylem development in Prunus flower buds and relationships to deep supercooling. Plant Physiol. 74:862-865.

Ashworth, E.N. and F.B. Abeles. 1984. Freezing behavior of water in small pores and the possible role in the freezing of plant tissues. Plant Physiol. 76:201-204.

Ashworth, E.N., G.A. Davis, and M.E. Wisniewski. 1989. The formation and distribution of ice within dormant acclimated peach flower buds. Plant Cell Environ. 12:521-528.

Biermann, J.C., C. Stushnoff, and M.J. Burke. 1979. Differential thermal analysis and freezing injury in cold hardy blueberry flower buds. J. Amer. Soc. Hort. Sci. 104:444-449.

Burke, M.J. and C. Stushnoff. 1978. Frost hardiness: a discussion of molecular causes of injury with particular reference to deep supercooling of water, p. 197-225. In: H. Mussel1 and R. Staples (ed.). Stress physiology in crop plants. Wiley, New York.

Cary, J.W. 1985. Freeze survival in peach and prune flowers. Plant Sci. Lett. 37:265-271.

Dorsey, M.J. 1934. Ice formation in the fruit bud of peach. Proc. Amer. Soc. Hort. Sci. 27:507-508.

Dorsey, M.J. and P.D. Strausbaugh. 1923. Winter injury to plum during dormancy. Bot. Gaz. 76: 113-142.

Dubochet, J., M. Adrian, J. Sepault, and A.W. McDowell. 1985. Cryroelectron microscopy of vitrified biological specimens. Trends Biochem. Sci. 10:143-146.

Esau, K. 1953. Plant anatomy. Wiley, New York.

George, M.F., M.J. Burke, and C.J. Weiser. 1974. Supercooling in overwintering azalea flower buds. Plant Physiol. 59:326-328.

Graham, P.R. and R. Mullin. 1976. A study of flower bud hardiness in azalea. J. Amer. Soc. Hort. Sci. 101:3-7.

Hayat, M.A. 1986. Basic techniques for transmission electron microscopy. Academic Press, Orlando, Fla.

Ishikawa, M. and A. Sakai. 1981. Freezing avoidance mechanisms by supercooling in Rhododendron flower buds with reference to water relations. Plant and Cell Physiol. 22:953-967.

Lewis, P.R. and D.P. Knight. 1977. Staining methods for sectioned material. vol. 5. part I. In: A.M. Glauert (ed.). Practical methods in microscopy. North Holland, Amsterdam, Netherlands.

Luft, J.H. 1961. Improvements in epoxy resin embedding methods. J. Biophys. Biochem. Cytol. 9:409-414.

Nus, J.L., J.J. Weigle, and J.J. Schradle 1981. Superimposed amplified isotherm differential thermal analysis system. HortScience 16:753-754. 


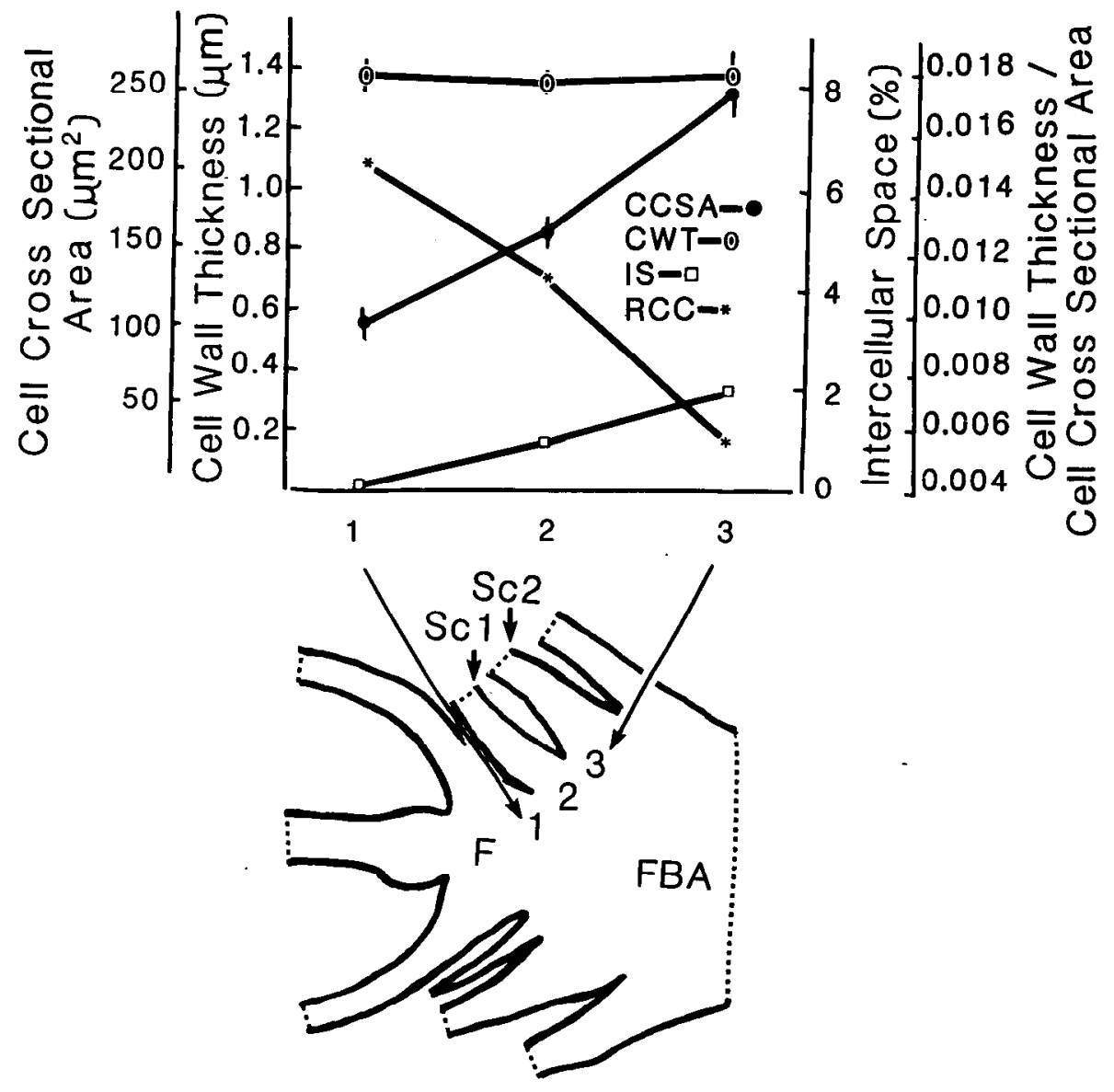

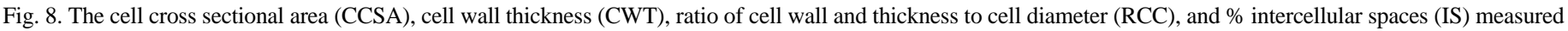

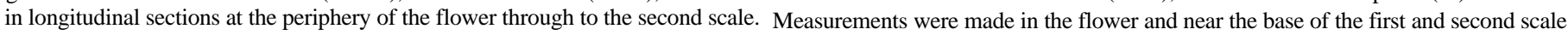
as indicated in the adjacent diagram. Vertical bars denote $\pm \operatorname{SE}(n=30)$.

Pierquet, P.C. and C. Stushnoff. 1980. Relationship of low temperature exotherms to cold injury in Vitis riparia Michx. Amer. J. Enol. Viticult. 3 1: 1-6.

Quamme, H.A. 1974. An exothermic process involved in the freezing injury of several Prunus species. J. Amer. Soc. Hort. Sci. 99:315-321.

Quamme, H.A. 1978. Mechanism of supercooling in overwintering peach flower buds. J. Amer. Soc. Hort. Sci. 103:59-61.

Quamme, H.A. 1983. Relationship of air temperature to water content and supercooling of overwintering peach flower buds. J. Amer. Soc. Hort. Sci. 108:697-701.

Quamme, H.A. 1991. Application of thermal analysis to breeding fruit crops for increased cold hardiness. HortScience. 26:513-517.

Quamme, H.A., R.E.C. Layne, and W.G. Ronald. 1982. Relationship of supercooling to cold hardiness and northern distribution of several cultivated and native Prunus species and hybrids. Can. J. Plant Sci. 62:137-148.

Sabatini, D.D., K. Bensch, and R.J. Barrnett. 1963. Cytochemistry and electron microscopy. The preservation of cellular ultrastructure and enzymatic activity by aldehyde fixation. J. Cell Biol. 17:19-58.

Sakai, A. 1978. Low temperature exotherms of winter buds of hardy conifers. Plant Cell Physiol. 19:1439-1446.

Sakai, A. 1979a. Deep supercooling of winter buds of Cornus florida L. HortScience 14:69-70.

Sakai, A. 1979b. Freezing avoidance mechanism in primordial shoots of conifer buds. Plant and Cell Physiol. 20:1381-1390.

Sakai, A., and W. Larcher. 1987. Frost survival of plants: Response adaptation to freezing stress. Springer-Verlag, Berlin.

SAS Institute. 1985. SAS user's guide: SAS/Graph, statistics, version 5. SAS Inst. Inc., Cary, N.C.

Steinbrecht, R.A. and K. Zierold. 1987. Cryrotechniques in biological electron microscopy. Springer-Verlag, Berlin.

Warmund, M.R., M.F. George, and B.G. Cumbie. 1988. Supercooling in 'Darrow' blackberry buds. J. Amer. Soc. Hort. Sci. 113:418-422. 